\title{
Clinical, virological, and pathological findings in a fatal case of $Q$ fever endocarditis
}

\author{
I. C. FERGUSON, J. E. CRAIK, AND N. R. GRIST \\ From the Medical Unit and Department of Pathology, Victoria Infirmary, Glasgow, \\ and the University Department of Virology, Ruchill Hospital, Glasgow
}

SYNOPSIS A case resembling subacute bacterial endocarditis in which blood cultures were repeatedly negative is described. The patient had had an influenza-like illness nine months before admission to hospital followed by intervening vague illness and loss of weight.

Serological tests revealed a high titre of complement-fixing antibodies to phase 1 and phase 2 antigens of Rickettsia burneti. After death R. burneti was isolated from the diseased aortic valve, liver, and kidneys.

Bodies morphologically resembling rickettsiae were seen in the aortic valve and in a very few renal tubule cells. No specific pathological lesions were found but there was a widespread stimulation of reticulo-endothelial cells particularly in the aortic valve cusps, spleen, lymph nodes, and renal glomeruli.

It is suggested that tests for $Q$ fever should be carried out in suspected cases of subacute bacterial endocarditis when blood culture is negative.

During the past 10 years it has become recognized that $\mathbf{Q}$ fever can occasionally persist as a chronic infection of man. Published evidence for this was recently reviewed by Robson and Shimmin (1959) who drew attention to the frequency of endocarditis and of peripheral vascular disturbances in such cases. Rickettsia burneti, the causal organism of $\mathbf{Q}$ fever, was isolated from the damaged heart valves of the cases described by Robson and Shimmin (Andrews and Marmion, 1959) and of cases reported by Evans, Powell, and Burrell (1959), by Smith and Evans (1960), and by Marmion, Higgins, Bridges, and Edwards (1960). The present paper describes a fifth case of $Q$ fever endocarditis confirmed by isolation of $R$. burneti from the diseased heart valve after death.

\section{CASE HISTORY}

In February 1959, a newspaper advertising manager aged 48 had an acute febrile illness with generalized aches and pains, which lasted for 10 days and was diagnosed clinically as influenza. Thereafter he never felt well, and during the next nine months he lost $2 \frac{1}{2}$ stones in weight. In June 1959, he experienced breathlessness on exertion for the first time, and this became progressively more severe until his admission to the Victoria Infirmary in November 1959, when he had symptoms of severe congestive cardiac failure. For a few days before admission he had transient left-sided pleural pain.

Received for publication 15 August 1961.
He gave a history of rheumatic fever in 1939 but in 1940, at an army medical examination, and in 1952, at a medical insurance examination, no cardiac abnormality had been found. In 1953 he was admitted to hospital suffering from fever and joint pains which persisted for three months. Mitral presystolic and systolic murmurs were heard at this time, and he had transient pericarditis. A chest radiograph showed cardiac enlargement with prominence of the pulmonary conus and the electrocardiogram showed mitral $\mathbf{P}$ waves with prolongation of the P-R interval. A diagnosis of acute rheumatism and mitral stenosis was made. He was discharged after four months and remained free from symptoms until the onset of his terminal illness in February 1959.

When admitted to hospital in November 1959 he was febrile $\left(99.4^{\circ} \mathrm{F}\right.$.) and axillary and epitrochlear lymph glands were palpable. He was in congestive cardiac failure, had finger clubbing and cardiomegaly with signs of left ventricular hypertrophy. Systolic and diastolic murmurs were heard over the whole praecordium but were maximal over the aortic area where a systolic thrill was palpable. The liver and spleen were enlarged two fingerbreadths and a haemorrhage was seen in the left optic fundus. A provisional diagnosis of subacute bacterial endocarditis was made.

Laboratory investigations revealed a normochromic anaemia, (Hb $11.3 \mathrm{~g} . / 100 \mathrm{ml}$. and a total white cell count of 6,400 per c.mm. of blood, with a normal differential distribution). The E.S.R. (Westergen) was $122 \mathrm{~mm}$. in the first hour. Repeated microscopic examinations of urine showed a few red blood cells per highpower field, and there was persistent slight albuminuria. 
Flocculation tests of liver function were abnormal on two occasions in January 1960 (thymol turbidity 17.4 Maclagen units per $100 \mathrm{ml}$. and zinc turbidity 24 units per $100 \mathrm{ml}$.). Serum albumin was $3.6 \mathrm{~g}$. per $100 \mathrm{ml}$., globulin $4.2 \mathrm{~g}$. per $100 \mathrm{ml}$., and paper electrophoresis of the serum revealed an increase in beta and gamma globulins. Two examinations for lupus erythematosus cells proved negative. Blood cultures were sterile on six occasions.

An electrocardiogram showed mitral $P$ waves and left ventricular strain. A chest radiograph showed enlargement of the left ventricle and prominence of the pulmonary conus.

COURSE OF ILLNESS AND TREATMENT Although blood cultures were negative, the clinical picture was so suggestive of subacute bacterial endocarditis that treatment was administered for this. The patient was given penicillin, 8 megaunits daily, for six weeks. The mild fever, $98^{\circ} \mathrm{F}$. to $99 \cdot 8^{\circ} \mathrm{F}$., subsided after three weeks but the spleen remained enlarged and the sedimentation rate raised $(132 \mathrm{~mm}$. in the first hour). Because the patient failed to respond to treatment, the possibility of $Q$ fever endocarditis was suspected and serological tests were carried out (see below). When positive results were obtained he was given $1 \mathrm{~g}$. of tetracycline daily for eight weeks but there was no significant improvement, the raised sedimentation rate and splenomegaly persisting. He remained afebrile, but congestive cardiac failure was intractable, and he died on 17 March 1960, in acute pulmonary oedema.

INVESTIGATIONS FOR Q FEVER For detection of antibodies to $R$. burneti serum specimens were tested by complement fixation against the phase 1 and phase 2 antigens (Stoker and Fiset, 1956) and also against heterologous $R$. prowazeki control antigen. A small-volume test was employed, using $0.1 \mathrm{ml}$. volumes each of antigen, serum, and complement (four $50 \%$ haemolytic units). Dilutions were made in barbitone-buffered calcium-magnesiumsaline. Tests were held at $4^{\circ} \mathrm{C}$. overnight, after which $0.1 \mathrm{ml} .2 \%$ optimally sensitized sheep cells were added to each cup and haemolysis was allowed to proceed at $37^{\circ} \mathrm{C}$. for 40 minutes. Antibodies to phase $2 R$. burneti antigen are formed in both acute and chronic $Q$ fever infections, but antibodies to phase 1 antigen have not been reported in acute infection of man and appear to be characteristic of the chronic disease (Marmion et al., 1960). Four sera from our case were tested, three collected during February 1960 and one at necropsy in March. All showed extremely high titres, 1 in 3,200 to 1 in 6,400 , of antibody to phase 1 and phase 2 antigens of $R$. burneti. The specificity of these reactions was shown by the negative results of complement-fixation tests with control typhus antigen and with influenza and adenovirus antigens; Paul Bunnell, Wassermann, and cold agglutination tests were also negative.

For isolation of $R$. burneti, fluid specimens of $20 \%$ extract of tissues collected at necropsy were inoculated intraperitoneally into guinea-pigs previously shown to be free of antibodies to $R$. burneti. Each specimen was injected into two guinea-pigs which were bled after six weeks and tested for antibodies indicative of $Q$ fever infection. By this method positive results indicating the presence of $R$. burneti were obtained with aortic valve, 으 liver, and kidney. The kidney and liver suspensions were non-infective when diluted tenfold, but the aortic valve $\overline{\vec{A}}$ suspension was infective to a dilution of 1 in 1,000 representing about 5,000 guinea-pig infectious units per gram of tissue.

In cases where animals injected with any specimen failed to develop antibody they were killed. Suspensions of their spleen were injected into a second pair of guineapigs, and if these animals also failed to develop antibodies $\overrightarrow{0}$ the test was considered negative. By this method $R$. ? burneti was not detected in blood clot or urine collected $\overrightarrow{\vec{\omega}}$ in March 1960, and negative results were also obtained $\stackrel{\omega}{\sigma}$ with mitral valve, myocardium from right and left ventricles, brain, spleen, and para-aortic lymph node.

\section{PATHOLOGICAL FINDINGS}

Necropsy was performed two and a half hours after $\stackrel{\omega}{\omega}$ death and precautions were taken to reduce the $ᄋ$ chances of accidental cross-infection, which is high $\longrightarrow$ in $Q$ fever (Marmion and Stoker, 1950). As far as we are aware no case of clinical $Q$ fever supervened.

The dissection was performed in a manner to $\overrightarrow{0}$ minimize bacterial contamination and cross-infection of the various organs. As these were exposed, specimens for rickettsial culture were collected witho separate sterile instruments and transferred to individual sterile jars. Portions of these specimens were also frozen for future fluorescent antibody study.

Examination of the body did not reveal pitting $\varrho$ oedema or excess fluid in the serous cavities. There $\overrightarrow{\overrightarrow{0}}$ was moderate clubbing of the fingers. No petechiae 3 or haemorrhages were seen.

The heart was considerably enlarged and weighed? $660 \mathrm{~g}$. All four cavities were grossly dilated and botho ventricles hypertrophied, particularly the left. The tricuspid and pulmonary valves were normal. The 3 aortic ring was of normal diameter but the cuspsio were thickened and stiff; they were neither per- 3 forated nor fused and there was no visible or palpable calcification. A single row of tiny brownish vegetations was present along the inner surface of eacho cusp near its free border. They glistened slightly as if covered by endothelium, and were not friable as inos classical bacterial endocarditis. The mitral cusps were thicker and less pliable than usual but the chordae tendineae were not thickened or contracted ${ }^{\omega}$ nor were the tips of the papillary muscles fibrosed. There were no visible vegetations.

The lungs were of normal size, the right weighing $500 \mathrm{~g}$. and the left $550 \mathrm{~g}$. Carbon pigmentation was much less than in the average city dweller. There was considerable congestion at the base of the left lung and abundant frothy fluid was easily expressed from the cut surface on digital pressure with residual oede matous pitting. Throughout the cut surfaces of bott? 
lungs were scattered dark red areas with ill-defined margins which varied in size from approximately $1 \mathrm{~cm}$. to 8 or $10 \mathrm{~cm}$. in diameter. The appearances were consistent with widespread pneumonitis.

The liver weighed $1,765 \mathrm{~g}$. and projected 3 to $4 \mathrm{~cm}$. below the costal margin. It was very firm and the cut surface showed the 'nutmeg' pattern of congestive cardiac failure. No other abnormalities were found throughout the digestive system.

The spleen was of normal shape but considerably enlarged, weighing $360 \mathrm{~g}$. The architecture of the cut surface was unaltered. The thoracic para-aortic lymph glands were slightly enlarged and very soft. No other enlarged nodes were found.

Both kidneys were enlarged, the right $190 \mathrm{~g}$. and the left $265 \mathrm{~g}$. The pelves were not dilated, the medullary and cortical striations were normal, the capsules stripped easily and there was no scarring or granularity of the surfaces.

The brain, spinal cord, endocrine glands, and the vertebral haemopoietic marrow appeared normal.

\section{HISTOLOGICAL EXAMINATION}

The cusps of the aortic valve were fibrosed and contained small vegetations composed of clumps of fuchsinophil fibrin clot surrounded by pale hyaline material which stained faintly blue with trichrome stains and was probably old fibrin. The vegetations did not produce 'cauliflower' outgrowths from the surface of the cusps, but were embedded in and intimately fused with the collagen (Fig. 1). In the hyaline material were occasional masses of tightly packed rickettsia-like bodies which appeared to be intracellular microcolonies whose host cells were in various stages of degeneration. Most frequently necrosis was so advanced that cells could not be positively identified (Fig. 2) and the microcolonies resembled those described by Andrews and Marmion (1959). Further stages of colonial disintegration could be identified round the large central colony in Fig. 2 up to disruption with liberation of free microorganisms. In addition there was a single cluster of less degenerate microcolonies which had an organoid architecture suggesting a group of cells 25 to 30 in number (Fig. 3). This cellular appearance was strengthened by the presence of a few dense basophilic structures resembling pyknotic nuclei.

The microcolonies of all types were scanty and many sections did not contain any. They measured 8 to $44 \mu$ and the contained micro-organisms were small, occasionally paired spheres or rods measuring 0.2 to $0.5 \mu$.

At the edge of the vegetations were large round and spindle cells, probably both macrophages and fibroblasts, while on and just below the surface there was proliferation of the endothelial cells lining the cusps. There were no polymorphonuclear leucocytes and few lymphocytes or plasma cells. Occasional mast cells were present in the adjacent fibrous tissue.

At the base of the cusps were groups of tightly packed, large, spindle-shaped cells which had distinct cell membranes and large spherical or ovoid open nuclei with single or double dense nucleoli. Many of these nuclei were of bizarre shape. We regard them as undifferentiated reticulum cells which are probably similar to the proliferating fibroblasts described, in their case, by Andrews and Marmion (1959) around aneurysms of the aortic sinus at the base of the infected cusps. They found no microorganisms in the fibroblasts, whereas most of the cells of the present case contained many rickettsialike organisms (Fig. 4). These organisms were undoubtedly intracellular and were morphologically identical with those found in the microcolonies in the vegetations, but in addition there were larger hyaline spherical bodies 1.0 to $3.0 \mu$ in diameter with similar staining reactions.

All the rickettsia-like bodies, whether intracellular or lying free in the tissue, stained dark blue with Giemsa, dull red with Macchiavello's method, and were Gram negative. Once the organisms had been identified with the selective stains they could be picked out in haematoxylin and eosin sections as faintly basophilic granules. In our material Macchiavello's method appeared to differentiate individual micro-organisms better than did Giemsa's.

The mitral valve cusps were fibrosed but there were no fibrinoid vegetations or cellular exudates. Rickettsiae could not be demonstrated.

The lungs showed pulmonary hypertension. The lumina of most of the pulmonary arteries were reduced in diameter and all three layers of the walls were thickened and fibrosed. Occasional mediumsized arteries were thrombosed without producing infarction. Heart failure cells were present in most of the alveoli and their capillaries were engorged. There were areas of very early interstitial pneumonia with collapsed alveoli whose walls were thickened by capillary distension, epithelial swelling, and fine fibrosis. A few large round cells, probably desquamated epithelium and very large macrophages, were present in the alveoli but erythrocytes and lymphocytes were scanty. The associated bronchi did not contain cellular exudate. A few of the less collapsed alveoli contained organizing exudate as well as the large round cells, and rarely there was polymorphonuclear leucocyte infiltration (Fig. 5). The lack of fibrosis and lymphocytic infiltration suggests that these areas of interstitial pneumonia were not of sufficiently long standing to have resulted from the acute illness of February 1959. The appearances are 


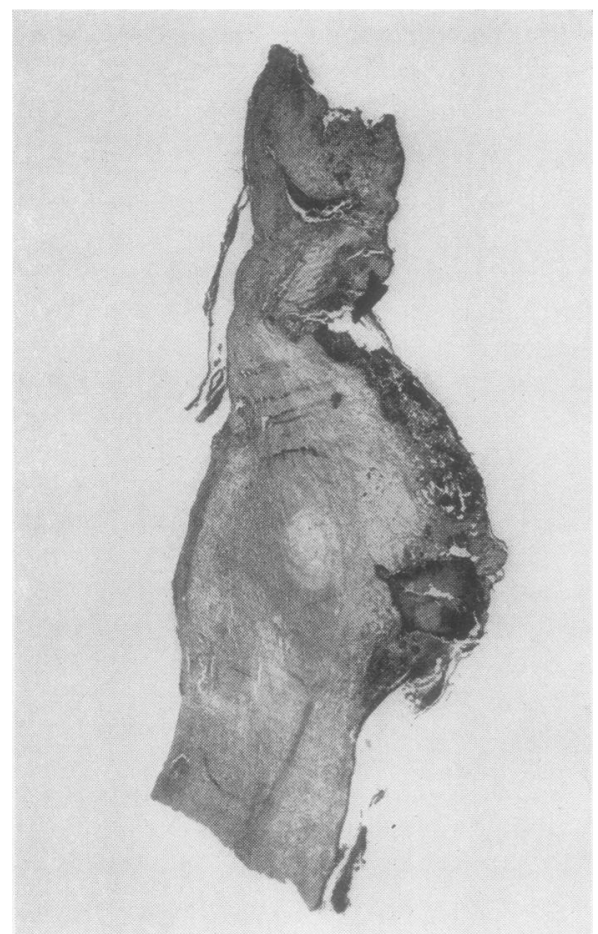

FIG. 1. An aortic valve cusp showing an infected vegetation covered by irregularly distributed dark fibrinoid material. The free border of the cusp is above. Haematoxylin and eosin $\times 8$.

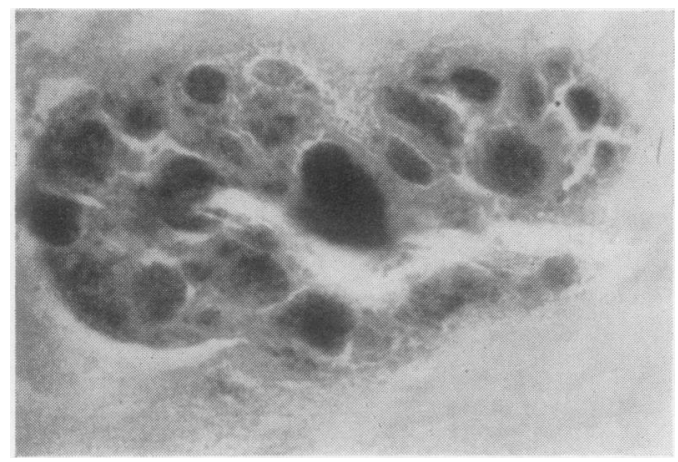

FIG. 3. A group of microcolonies from an aortic vegetation. The architectural arrangement suggests a group of cells containing intracytoplasmic rickettsiae. Macchiavello $\times 650$.

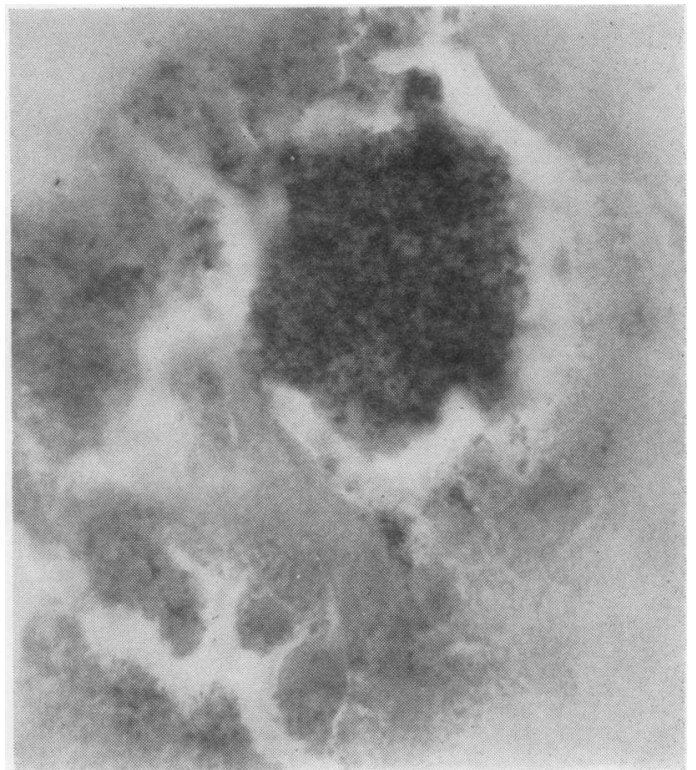

FIG. 2. A large microcolony from an aortic valve vegetation containing tightly packed rickettsia-like bodies. Round the main colony there are many disrupted and partially degenerate smaller colonies. None of these microcolonies is clearly intracellular. Macchiavello $>$ 1,100 .

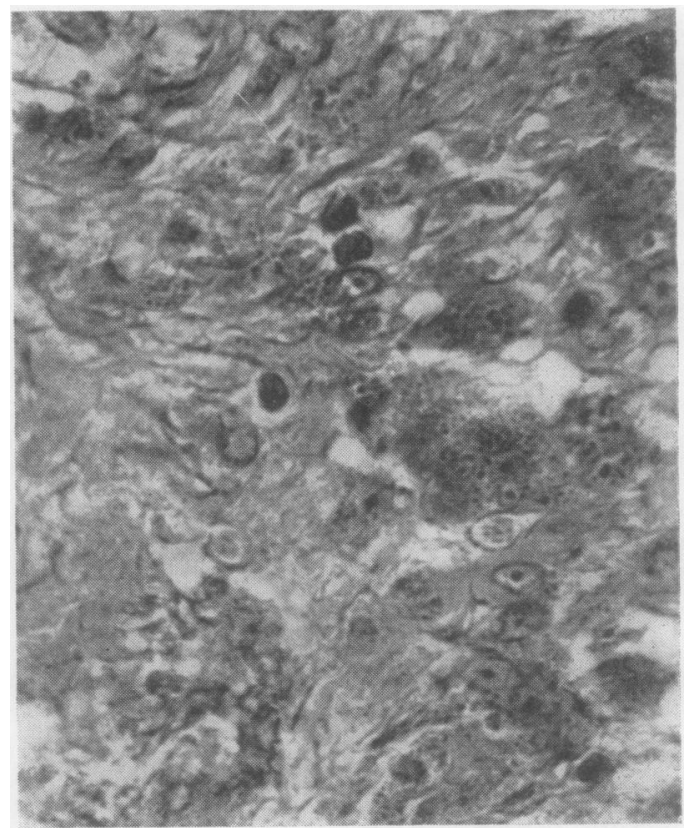

FIG. 4. Large reticulum cells invading the base of an $\mathrm{Q}$ infected aortic valve cusp. Most of the cells contain rickettsia-like organisms resembling those seen in the vegetations (Figs. 2 and 3). These microcolonies are undoubtedly intracellular. Macchiavello $\times 1,100$. 
more in keeping with incomplete resolution of a recent pneumonitis possibly arising from rickettsiaemia associated with the endocarditis.

The sinusoids of the spleen were intensely engorged. They contained many lymphocytes and plasma cells in addition to blood, and the endothelial cells were swollen. The lymphoid tissue was not affected. In the para-aortic lymph nodes the sinus endothelium was hyperplastic and the cells swollen and cuboidal. Small and large plasma cells were present both in the sinuses and in the follicles (Fig. 6). No rickettsiae could be demonstrated in either the spleen or the lymph nodes.

The liver showed marked passive venous congestion with dilatation of the blood capillaries and fine fibrosis of their walls. The portal tracts were lightly infiltrated by lymphocytes and there was some thickening of periportal reticulin as is seen after infective hepatitis (Himsworth, 1947). No rickettsiae could be demonstrated histologically.

In the kidneys there was generalized diffuse thickening of the basement membranes of the tufts and capsules of the glomeruli, with swelling and slight proliferation of the endothelial cells (Fig. 7) suggesting mild membranous glomerulonephritis. There were no adhesions or epithelial crescents and the focal embolic glomerular lesions of subacute bacterial endocarditis were not seen. In Macchiavellostained preparations occasional epithelial cells of the first convoluted tubules contained tiny dull red bodies. These stood out from the cytoplasmic granules of the epithelial cells which did not stain by this method. They resembled the rickettsia-like organisms found in the aortic valve cusps but did not form such tightly packed masses (Fig. 8).

Sections from myocardium, endocrine glands, brain, and vertebral haemopoietic marrow showed no abnormalities and no rickettsiae were found.

\section{DISCUSSION}

$Q$ fever is a rickettsial infection of world-wide distribution affecting many species. In Britain, the main reservoir of infection appears to be sheep and cattle (Marmion and Stoker, 1958), the prevalence being lower in Scotland than in England or Wales (Slavin, 1952; Grist, 1956). Chronic silent infections are well recognized in sheep and cattle and apparently healthy dairy cows have been observed to excrete $R$. burneti in milk for several years (Grist, 1959). Although the human disease is best known in its acute form with pneumonia, fever, and severe headache, Marmion, Stoker, McCoy, Malloch, and Moore in 1953 drew attention to atypical illnesses and suggested that 'patients with a cardiac abnormality may be abnormally liable to chronic infection with $R$. burneti, or even that this organism, like some other rickettsiae, may occasionally cause lesions in the vascular system, giving rise, for example, to endocarditis, cerebral haemorrhage, and embolic phenomena'. Of the five reported patients from whose heart valves $R$. burneti was isolated, the histories of four suggested previous rheumatic disease; in the fifth case (Evans et al., 1959) the endocarditis was superimposed on calcific aortic stenosis. It therefore seems probable that $\mathbf{Q}$ fever endocarditis, like subacute bacterial endocarditis, becomes established during an acute episode by deposition of organisms on distorted or roughened valve cusps. The distribution of the rickettsial lesions between the mitral and aortic valves, two mitral as against three aortic in the five reported cases, is at variance with both rheumatic and subacute bacterial endocarditis, but in such a small series this difference is not significant.

The isolation of rickettsiae from the liver is of interest since hepatitis is a recognized complication of acute $Q$ fever, particularly in patients with protracted illness (Clark, Lennette, Railsback, and Romer, 1951). The raised thymol and zinc turbidities gave biochemical confirmation of liver cell damage. Histological methods did not reveal any rickettsiae but, in addition to the centrilobular fibrosis which might well result from congestive cardiac failure alone, there was some thickening of the periportal reticulin network suggesting recent hepatitis with almost complete resolution.

$R$. burneti may be isolated from the urine of acute cases. In a case of illness resembling subacute bacterial endocarditis after an attack of $Q$ fever which was investigated by Huebner, the organism was isolated from both blood and urine more than a year after the original acute episode (Andrews and Marmion, 1959; Huebner, personal communication). Whittick (1950) was able to demonstrate rickettsiae in many organs, including tubule cells, glomeruli and interstitial tissues of the kidney in a fatal case of acute $\mathbf{Q}$ fever. In the present case the rickettsialike bodies in the proximal renal tubule cells (Fig. 8) have not as yet been specifically identified as $R$. burneti, but the positive culture makes their presence more suggestive.

Failure to isolate $R$. burneti from the spleen and other specimens may be due to the neutralizing effect of the extremely high titres of antibody (Abinanti and Marmion, 1957).

It seems likely that apart from the infected vegetations there are no specific pathological lesions in $\mathbf{Q}$ fever endocarditis, and focal embolic glomerulitis has not been found in any of the cases so far described, although this lesion is a feature of subacute bacterial endocarditis. The presence of large numbers of plasma cells in the spleen and lymph 


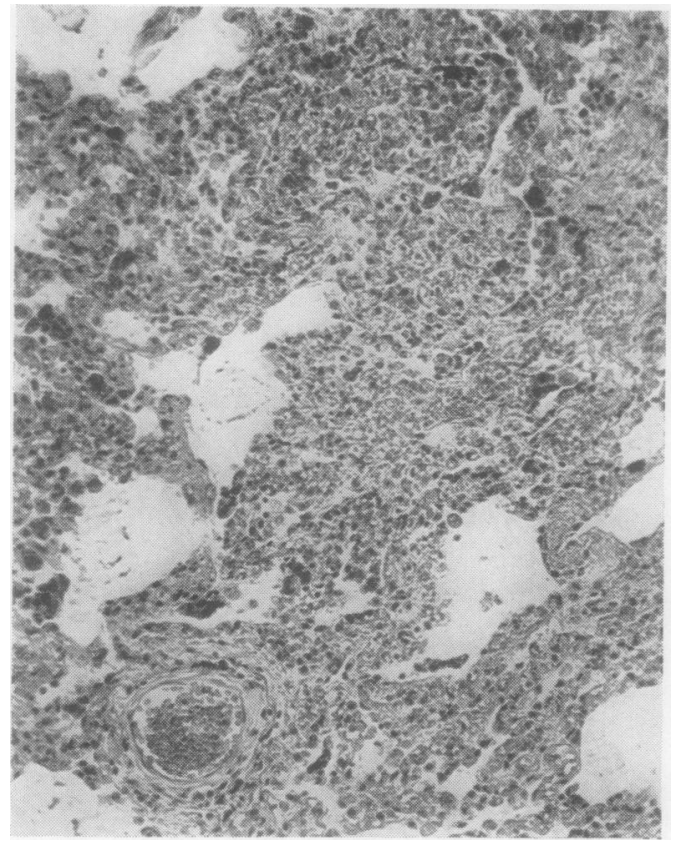

FIG. 5

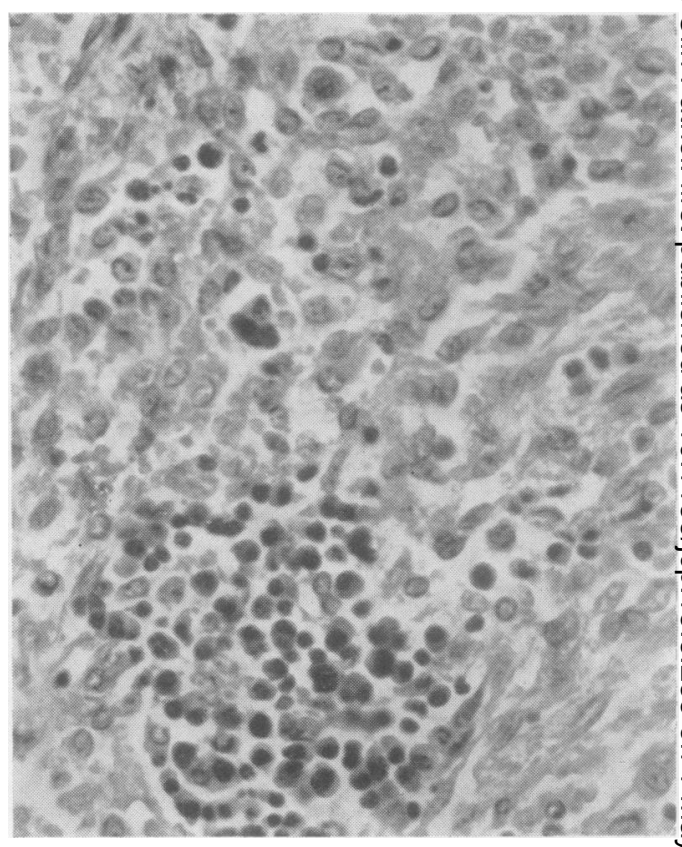

FIG. 6

FIG. 5. Lung showing a zone of interstitial pneumonia with collapsed alveoli and swollen epithelial cells. A thick-walled? pulmonary artery, indicating pulmonary hypertension, is present in the lower left of the field. Haematoxylin and eosin $\times 130$. FIG. 6. Lymph gland showing swollen endothelial cells packing the sinuses and infiltrates of large plasma cells. Haematoxylin and eosin $\times 400$.

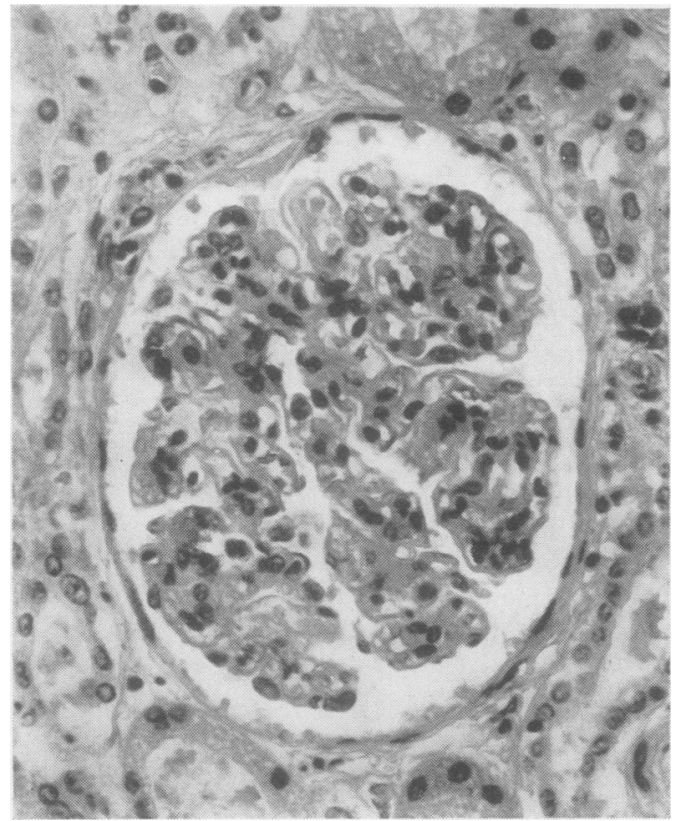

FIG. 7

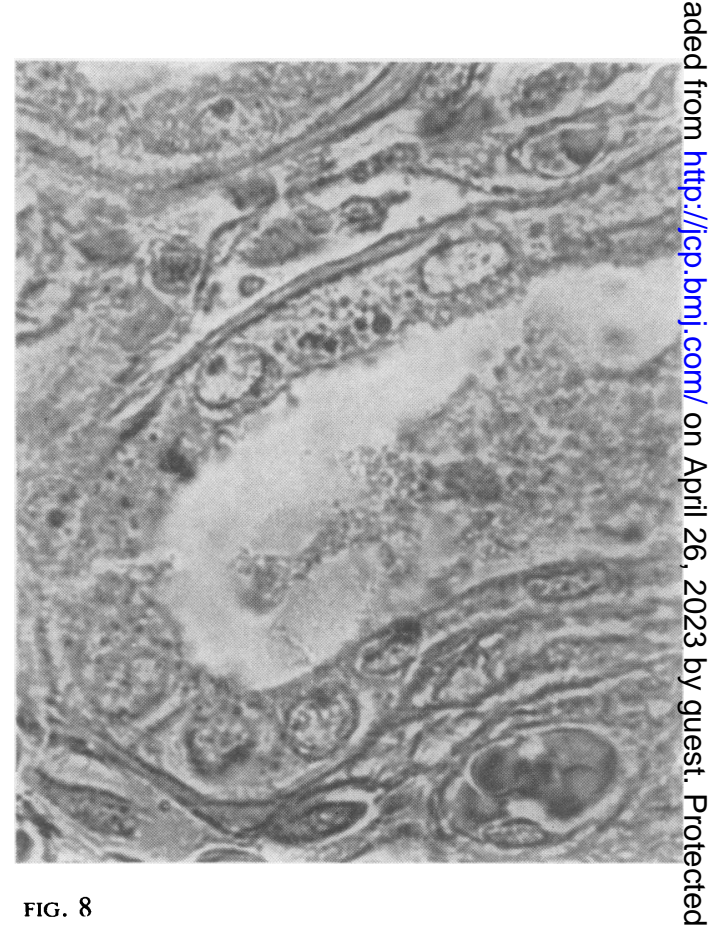

FIG. 7. Renal glomerulus showing minimal glomerulitis. The basement membranes of the tufts are thickened and the endothelial cells are both swollen and increased in numbers. Haematoxylin and eosin $\times 300$.

FIG. 8. A proximal convoluted tubule from kidney. In some of the cells there are tiny black spherules resembling the rickettsia-like bodies found in the infected aortic valve cusps (c.f. Figs. 2, 3, and 4). Macchiavello $\times 1,100$. 
glands may well be related to the high titre of antibodies. In the present case, and to some extent in previously published cases, there appears to be a generalized stimulation of the reticulo-endothelial system:-

1 At the edge of the hyaline vegetations there is swelling and proliferation of the endothelial cells lining the aortic valve cusp (Fig. 1).

2 At the base of the infected cusps there is an ingrowth of large reticulum cells, some of which undergo differentiation to fibroblasts (Fig. 4). Andrews and Marmion (1959) and Evans (personal communication) noted similar large cells in their cases.

3 In the spleen and in the enlarged lymph glands the endothelial cells of the sinuses were both hypertrophic and hyperplastic (Fig. 6).

4 The renal glomeruli showed a mild glomerulitis with thickening of the basement membranes of the tufts and swelling and some proliferation of the endothelial cells (Fig. 7). This is probably a mild or early form of the chronic lobular glomerulonephritis reported by Marmion et al. (1960). They remarked that this was an unusual feature although it had been described in subacute bacterial endocarditis.

As $R$. burneti is an obligate intracellular parasite it is of considerable interest that in the infected vegetations the microcolonies were not clearly intracellular (Fig. 2). Marmion and his colleagues comment on this feature in both their cases (Andrews and Marmion, 1959; Marmion et al., 1960). Evans (personal communication) also reports the presence of extracellular organisms in the infected cusps of two published cases (Evans et al., 1959; Smith and Evans, 1960) and of a third unpublished case. Further, in all three of his cases there were intracellular organisms which were confined to healthy large typical reticulum cells and none could be seen in degenerate cell-like structures. In the present case, on the other hand, the micro-organisms at the bases of the cusps were clearly intracellular (Fig. 4) and we were able to trace stages in the degeneration of parasitised cells (Fig. 3) up to necrosis and final rupture leaving rickettsiae lying free in the tissues (Fig. 2).

From the clinical point of view, it is important to suspect the possibility of $\mathbf{Q}$ fever in cases of apparent subacute bacterial endocarditis with persistently negative blood cultures. The simplest diagnostic test is examination of the patient's serum for complementfixing antibodies to $R$. burneti; the accumulation of evidence suggests that phase 1 antibodies may be diagnostic of chronic $Q$ fever. The prognosis in $Q$ fever endocarditis is grave, since all the reported cases have died in cardiac failure. The organisms proliferating within living cells may be partly protected from circulating antibiotics and antibodies by the cell membrane, at least until cellular degeneration destroys this biological barrier; whereas the extracellular organisms of subacute bacterial endocarditis are not so protected and the infection often responds to antibiotic therapy. It is likely that mildly infected cells in chronic $\mathbf{Q}$ fever continue to proliferate, thus providing uninterrupted cover for succeeding generations of rickettsiae (Fig. 4), and an unfailing reservoir of fresh infection. On the other hand, actively growing organisms in acute exacerbations and in primary acute infections disrupt the host cell and are exposed to the direct action of antibodies and antibiotics; such action possibly explains the presence of the pale degenerate organisms seen in Fig. 3.

$R$. burneti is insensitive to penicillin and streptomycin; sulphonamides stimulate the growth of rickettsiae and are contraindicated. Tetracyclines and chloramphenicol are merely rickettsiostatic, and may have little chance to exert their effect against organisms which, in chronic lesions, are perhaps in a relatively inactive metabolic condition. In these circumstances it is fortunate that $\mathbf{Q}$ fever endocarditis is an uncommon condition. Further work is required to estimate its frequency, but only one case of $\mathbf{Q}$ fever endocarditis was found among 56 cases of suspected or proved subacute infective endocarditis investigated in Yorkshire by Marmion et al. (1960).

We thank Dr. L. G. Bruce, consultant bacteriologist to the Victoria Infirmary, for bacteriological investigations; Professor M. G. P. Stoker, Institute of Virology, Glasgow University, for phase $1 R$. burneti and control typhus rickettsial antigen; Dr. B. P. Marmion, Virus Laboratory, Public Health Laboratory, Leeds, for control antiserum to phase $1 R$. burneti; Dr. R. J. Huebner, Laboratory of Infectious Diseases, National Institutes of Health, Bethesda, Md., U.S.A., for permission to cite an unpublished case of chronic $Q$ fever; and Dr. A. D. Evans for observations on the distribution of rickettsiae in his cases. We are grateful to Dr. Ian Murray and Dr. W. B. Davis for helpful criticism of the manuscript. We thank Mr. H. C. Gray for the photomicrographs.

\section{REFERENCES}

Abinanti, F. R., and Marmion, B. P. (1957). Amer. J. Hyg., 66, 173. Andrews, P. S., and Marmion, B. P. (1959). Brit. med. J., 2, 983.

Clark, W. H., Lennette, E. H., Railsback, O. C., and Romer, M. S. (1951). A.M.A. Arch. intern. Med., 88, 155.

Evans, A. D., Powell, D. E. B., and Burrell, C. D. (1959). Lancet, 1, 864. Grist, N. R. (1956). Scot. med. J., 1, 173.

- (1959). Vet. Rec., 71, 839.

Himsworth, H. P. (1947). Lectures on the Liver and its Diseases. Blackwell, Oxford.

Marmion, B. P., Higgins, F. E., Bridges, J. B., and Edwards, A. T. (1960). Brit. med. J., 2, 1264.

$\longrightarrow$, and Stoker, M. G. P. (1950). Lancet, 2, 611.

- (1958). Brit. med. J., 2, 809.

, McCoy, J. H., Malloch, R. A., and Moore, B. (1953). Lancet, 1, 503 .

Robson, A. O., and Shimmin, C. D. G. L. (1959). Brit. med. J., 2,980. Slavin, G. (1952). Vet. Rec., 64, 743.

Smith, W. G., and Evans, A. D. (1960). Lancet, 2, 846.

Stoker, M. G. P., and Fiset, P. (1956). Canad. J. Microbiol., 2, 310. Whittick, J. W. (1950). Brit. med. J., 1, 979. 